\title{
Microstructural analysis of concretes manufactured with recycled coarse aggregates pre-soaked using different methods
}

\author{
Z. Sánchez-Roldán, I. Valverde-Palacios $\bowtie$, I. Valverde-Espinosa, M. Martín-Morales \\ Department of Building Construction, ETS de Ingeniería de Edificación, University of Granada, (Granada, Spain) \\ $\triangle$ nachoval@ugr.es
}

Received 3 December 2019

Accepted 2 April 2020

Available on line 17 July 2020

\begin{abstract}
Recycled concrete has a microstructure more complex than natural concrete, as it includes new interfacial transition zones, the quality of which is conditioned by the state of humidity of the aggregates used, which in turn will affect the final properties of the concrete. Bearing in mind the greater absorption capacity of recycled aggregates, it is important to improve its properties by means of a treatment method that is capable of reducing the negative effects that this may produce in the new concrete. Therefore, the influence of the presoaking method of recycled aggregates on the formation of the microstructure of concretes manufactured with these aggregates is analysed, to determine which treatment is the most effective for the production of concretes for non-structural use. The results show that the microstructure of the evaluated concretes differs according to the treatment method used, the most optimal method being one that uses aggregates without pre-soaking.
\end{abstract}

KEYWORDS: Concrete; Interstitial Zone; Waste treatment; Microstructure; Image analysis.

Citation/Citar como: Sánchez-Roldán, Z.; Valverde-Palacios, I.; Valverde-Espinosa, I.; Martín-Morales, M. (2020) Microstructural analysis of concretes manufactured with recycled coarse aggregates pre-soaked using different method. Mater. Construcc. 70 [339], e228. https://doi.org/10.3989/mc.2020.16919

RESUMEN: Análisis microestructural de hormigones fabricados con áridos gruesos reciclados premojados según diferentes métodos. El hormigón reciclado tiene una microestructura más compleja que el natural, ya que incluye nuevas zonas de transición interfacial, cuya calidad está condicionada por el estado de humedad de los áridos utilizados, lo que a su vez repercutirá en las propiedades finales del hormigón. Teniendo en cuenta la mayor capacidad de absorción de los áridos reciclados, se considera fundamental la mejora de sus propiedades, mediante un método de tratamiento que sea capaz de disminuir los efectos negativos que éstos puedan producir en el hormigón. Por ello, se analiza la influencia del método de premojado de los áridos reciclados en la formación de la microestructura de hormigones fabricados con estos áridos, para así determinar qué tratamiento es el más eficaz. Los resultados muestran que la microestructura de los hormigones evaluados difiere según el método de tratamiento utilizado, siendo el más óptimo el que utiliza los áridos sin premojar.

PALABRAS CLAVE: Hormigón; Zona interfacial; Tratamiento de residuos; Microestructura; Análisis de imágenes.

ORCID ID: Z. Sánchez-Roldán (https://orcid.org/0000-0002-3157-9778); I. Valverde-Palacios (https://orcid.org/00000002-3550-3092); I. Valverde-Espinosa (https://orcid.org/0000-0002-5890-2723); M. Martín-Morales (https://orcid. org/0000-0002-0337-1718)

ABBREVIATIONS: ITZ: interfacial transition zones; NA: natural aggregate; NCA; natural coarse aggregate; NFA: natural fine aggregate; OM: optical microscopy; RA: recycled aggregate; RAC: recycled aggregate concrete; RCA: recycled coarse aggregate; w/c: water/cement; $\mathrm{WA}_{24 \mathrm{~h}}$ : water absorption after 24 hours.

Copyright: (C) 2020 CSIC. This is an open-access article distributed under the terms of the Creative Commons Attribution 4.0 International (CC BY 4.0) License. 


\section{INTRODUCTION}

The construction industry is the sector with the greatest environmental impact, as it consumes a large amount of natural resources and energy, and simultaneously produces significant amounts of waste. Concrete is the most widely used material in this industry, due to its versatility and easily alterable properties; sustainability in this field can be improved by maximising the use of existing resources within the framework of the circular economy, and minimising its environmental impact $(1,2)$. Given that one of the main uses of aggregates is in the manufacture of concrete (3), it is logical to assume that the fundamental use of recycled aggregates (RA) is in the production of more sustainable concrete (4). This construction material is defined in Annex 15 of Instruction EHE-08 (5) as that manufactured with recycled coarse aggregate (RCA) from the crushing of concrete waste. In this context, important research activity is being carried out on the use of RA in the manufacture of concrete, the results of which have indicated that its physicalmechanical and durability behaviour is marked by the composition of the waste used, as well as by the mix design used (6-8).

Recycled aggregate concrete (RAC) has a much more complicated microstructure than conventional concrete. Concrete manufactured with recycled material includes three distinct and clearly differentiated interfacial transition zones (ITZs): adhered cement mortar-cement paste, RA-cement paste and original mortar-aggregate, in addition, there is a zone that joins the particles of natural aggregate (NA) with the cement paste, as shown in Figure 1. The adhered cement mortar itself includes many microcracks, which are formed during the production of RA (and during the useful life of the original concrete), and a high porosity $(9,10)$, making it a weak point. This means that its physical, and to a greater extent mechanical, properties condition the concrete manufactured with these aggregates.
Taking into account the complexity and heterogeneity of the internal structure of concrete, its complete characterisation involves the determination of the types, quantities and distribution of all its constituents (10), both from a macroscopic point of view (as it is composed of aggregate particles, coarse and fine, dispersed in a cement paste matrix) and at a microscopic level (as it is made up of several transition zones linking the aggregate particles with the paste or mortar, as well as molecular and crystalline structures, capillary pores and gel pores). This is because the characteristics of each independent phase or component of concrete and the interaction between them can help in an understanding of the mechanical and durability properties of the material. Of the constituents of RAC, the ITZ, which is essentially composed of three phases (solid, aqueous and porous), is characterised by a relatively low concentration of unhydrated cement particles as it approaches the interface, and a high water content due to the effects of exudation around the aggregate, among other factors $(11,12)$. This results in high porosity and more noticeable microcracking, and consequently lower strength and greater deformation (13).

A wide variety of opinions on this subject can be found in the literature; some authors consider that the interface of the mortar is a zone of greater weakness, due to the presence of pores and cracks that can diminish the properties of the RAC (14, 15). Others have even found that when RA comes from high quality concretes, this will be reflected in the quality of the adhered mortar and subsequently in that of the hardened material, meaning that this does not always have a negative effect on the transition zone (16). It is for this reason that improvements in the microstructure of the RA are presented as a subject of considerable interest, since this microstructure can be strongly influenced by the greater water absorption capacity of these aggregates, which also increases as the particle size of the aggregate decreases, and by the ways in which
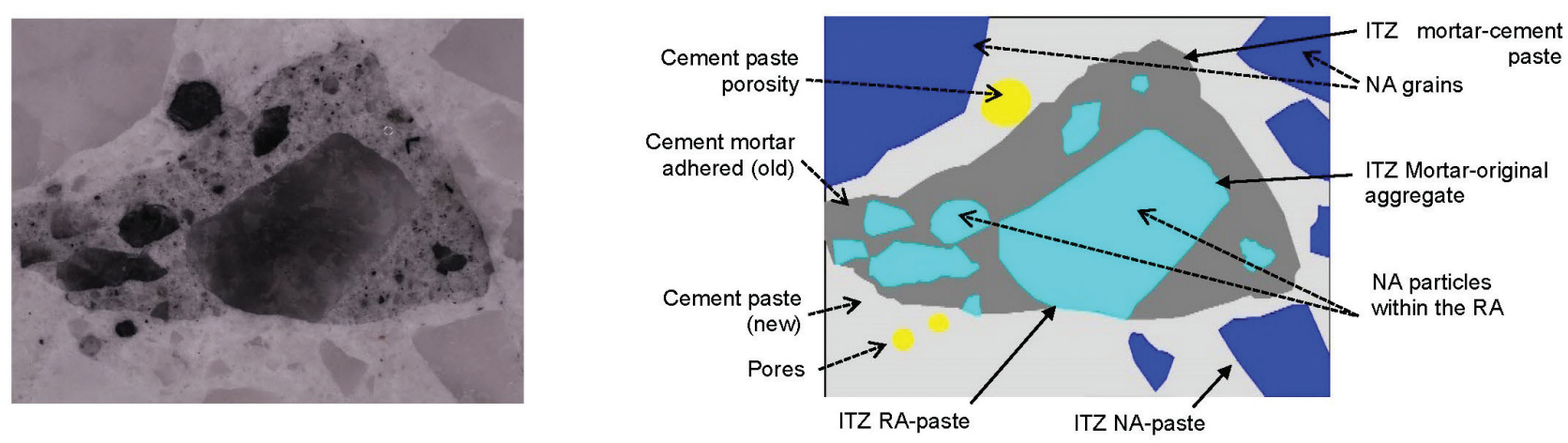

FIGURE 1. Internal structure of a RA forming part of a new concrete; image at $5 \mathrm{x}$ (left) and pictogram (right). 
this can be mitigated (via pre-treatment methods) (17-19). Hence, various studies have analysed the humidity conditions of the RA and how the mix design used (mainly the total water/cement or w/c ratio) influences the properties of the concrete, in both its fresh and hardened states $(6,20-22)$. On the other hand, a small number of authors have focused on the analysis of the microstructure of this type of concrete (23-26), and mainly on the formation of its internal structure when using RA in different states of humidity: dry, pre-soaked and saturated with a dry surface. All of these authors agree that the RA-cement paste interface has different characteristics depending on the mixing method used, as this will affect the final properties of the concrete $(24,25,27)$.

Many techniques have been used to evaluate structure of concrete pores. Every one of them is suitable for a specific size range. Among these microscopic techniques can be found optical microscopy (OM) and scanning electron microscopy (SEM), among others. The OM is older but still the most affordable modern tool. OM magnifies small objects allowing the observer to directly see structures which are below human eye's resolving power around $0.1 \mathrm{~mm}$. On the other hand, the SEM is a tool intended mainly to study the surface of solids with a large magnification. The images are qualitatively similar to those obtained through OM, however the SEM possesses a higher resolution and depth of field. Yet the SEM has a relatively higher cost (28). Despite its, most of the studies on RAC microstructure investigations used images from SEM to characterize the morphological features of the ITZ, or even other much more expensive techniques $(24,29,30)$. Considering that the resolution of the imaging determines the range of pore sizes accessible, OM may be appropriate for studying the pore formation and the distribution of their components on $\mathrm{RC}$ microstructure, given that it is widely used in petrographic and metallographic studies; therefore, it can also be valid for use in both laboratory and industrial-scale applications (31-33). Even so, few studies have used it to study RAC (34).

Thus, taking into account the complexity of the internal structure of the RACs and the fact that the treatment used to compensate for the physical deficiencies of the RA conditions the microstructure of the concrete, this work focuses mainly on a study of the characterisation of the porous and microstructural systems of RACs manufactured using five different pre-soaking methods. These were compared with a concrete produced with RA without presoaking, and one produced with NA, which is used as a reference (22). This was done with the aim of determining which treatment improved the microstructural and mechanical behaviour of concretes manufactured with RA for non-structural use, to subsequently identify which is the most effective for its reproduction at an industrial level. For this purpose, a direct observation technique involving OM was used to measure the porosity and pore size distribution. In addition, digital image analysis provided a broad view of the distribution of all concrete constituents, as well as the formation of the ITZ surrounding each of them.

\section{MATERIALS AND METHODS}

This study was based on information reported in a previous work (22) in which the characterisation of the aggregates, the dosage and the analysis of the physical and mechanical properties of the different concretes were carried out, with RA that was previously treated using five different methods. This information is summarised below.

\subsection{Materials}

The following materials were used for the manufacture of the studied concretes: natural aggregates of fine fractions, $0 / 4 \mathrm{~mm}$ (NFA) and coarse $4 / 16 \mathrm{~mm}$ (NCA) obtained from the crushing of limestone from Sierra Elvira, in Granada, Spain; recycled aggregates of fraction 4/16 mm (RCA) obtained from the crushing and screening of different construction and demolition wastes and deposited in a treatment plant in Alhendín, Granada, Spain; white cement with high initial resistance (BL II/A-L 42.5R UNE 80305); and a new generation of superplasticising admixture (Chryso®fluid Optima 227).

The recycled granular material used was mainly composed of concrete $(89 \%)$ and natural stone $(9.1 \%)$, in addition to a small amount of asphalt $(1.8 \%)$ and a low content of ceramic material $(0.2 \%)$, among other minority components. According to EHE-08 (5) and EN 12620 (35), RCA has a favourable granulometry for use in the manufacture of concrete, and the quantity and quality of the fines present in this type of aggregate were adequate, although it had a content of particles lower than $4 \mathrm{~mm}(6.65 \%)$ that was slightly higher than that permitted $(4 \%)$. The density $\left(2.54 \mathrm{~kg} / \mathrm{dm}^{3}\right)$, resistance to fragmentation (34) and water absorption, $\mathrm{WA}_{24 \mathrm{~h}}$ $(2.1 \%)$ of RCA, compared to those of NCA (2.61 $\mathrm{kg} / \mathrm{dm}^{3}, 31$ and $0.4 \%$, respectively), were affected by the adhering mortar, although in all cases they met the corresponding regulatory requirements $(5,35)$.

\subsection{Concrete samples}

The pre-soaking technique is used to reduce the exchange of water between the RA and the cement paste by filling the pores and cracks of the aggregate in such a way as to guarantee that the aggregate reaches an optimum level of humidity. This is done to avoid subtracting water from the cement hydration process, and in turn to provide an adequate consistency to the mixture $(7,8,36)$. 
Based on this, and in order to determine the effects of pre-soaking on the microstructure of the $\mathrm{RAC}$, the studied concretes were manufactured according to five methods: four of these were taken from the literature (Method 1 to 4) (7, 37-39), and a fifth was proposed by the authors (Method 5). The differences between these methods are summarised in Figure 2, showing the respective mixture components and the order in which they have been added, the data related to the water content (pre-soaking water and total water), and the pre-soaking and mixing times required for each method. The methods used differed in terms of the amount of pre-soaking water used $(12 \%, 50 \%, 70 \%, 80 \%$ and $100 \%)$, the pre-soaking time (2, 5 and 10 minutes), the total mixing time $(12,15$ and 20 minutes) and the total water $(8 \%, 8.9 \%$ and $9 \%)$, calculated on the basis of the added water content plus the mixing or effective water. Method 5 was based on the general need to pre-soak the RCAs so that they do not subtract water from the other materials, but without adding additional water to the mixture. In this case, the aggregates were pre-soaked with $80 \%$ of the mixing water, a sufficient quantity to guarantee adequate moisture of the aggregates, and the rest of the solid components were subsequently added, together with the remaining $20 \%$ of the water, which was necessary to dilute the liquid admixture. In this method, unlike the others, the total w/c ratio remained unchanged although the RA was pre-soaked.

Five concretes were manufactured with total replacement of the NA coarse fraction with RA (R-Series 1 to R-Series 5). These were then compared with a concrete with RA without pre-soaking (R-Series 0), and with a concrete with NA (N-Series $\mathrm{C})$. All of the concretes had a fixed composition regarding the content of the following materials: NCA or RCA $(50 \%)$, NFA $(33 \%)$, cement $(17 \%)$, admixture $(0.80 \%)$, water for mixing or effective ( $8.0 \%$, calculated by mass of cement plus aggregate) and effective w/c ratio (0.48). Physical-mechanical properties obtained from the concretes produced are showed in Table 1.

\subsection{Microstructural characterisation of hardened concrete}

Direct observation via optical microscopy was used to evaluate the studied concretes, and three samples of each were analysed, obtained at random from different points of specimen. As this is a non-standard technique, the methodology used is

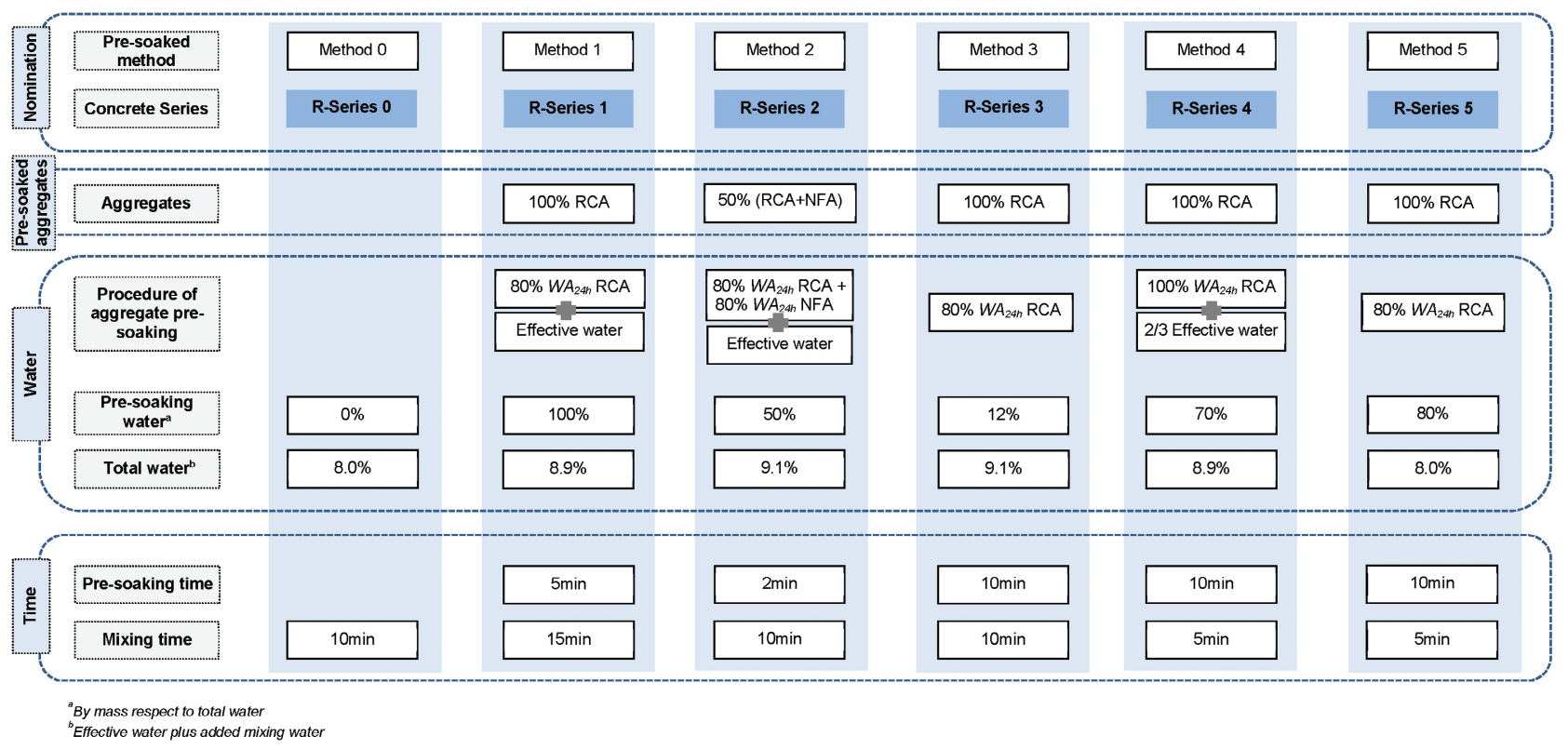

FIGURE 2. Components of mixtures and making process.

TABLE 1. Physical-mechanical properties of the concretes produced.

\begin{tabular}{lcccccccc}
\hline & N-Series C & R-Series 0 & R-Series 1 & R-Series 2 & R-Series 3 & R-Series 4 & R-Series 5 \\
\cline { 2 - 8 } Consistency type (5) & Soft & Plastic & Fluid & Liquid & Plastic & Soft & Dry \\
\hline Compressive strength-28days (MPa) & 55.42 & 55.54 & 51.75 & 46.67 & 50.39 & 46.09 & 54.65 \\
\hline
\end{tabular}


described below. This approach made it possible to analyse the porosity of the concrete by visualising its microstructure, as it considers large two-dimensional areas of the same sample $\left(4-5 \mathrm{~cm}^{2}\right)$ in order to quantify the quantity and distribution of its constituents at the level of its internal structure (28).

In the optical microscopy technique applied here, a Nikon Epiphot 200 petrographic optical microscope with polarised light and inverted plate was used, equipped with a $7 \mathrm{Mp}$ digital camera that allowed images to be obtained with a maximum resolution of $0.07042 \mu \mathrm{m}$ per pixel at 100x, corresponding to a visual region of $15599.59 \mu \mathrm{m}^{2}$. This camera was connected to a computer, where it transformed the digitalised image from pixels to $\mu \mathrm{m}$ using the Perfect Image (Clear Vision) software, taking into account the lens used $(5 x, 10 x, 20 x, 50 x$ or $100 x)$.

The correct preparation of samples is a very important factor in obtaining the best performance from microscopic observations (31). For this experiment, $2 \mathrm{~cm}$ cubes were cut from the standard specimen using a cutter (Struers Labotom-3) equipped with a special cutting disc for stone material. The air inside the pores and fissures was removed by a vacuum filler (Struers CitoVac) for one hour at low pressure (4.5 to 6 bar), allowing the low-viscosity epoxy resin (Epofix Resin, Struers) to penetrate all the pores of the filled concrete specimen. After hardening of the impregnation material, an initial two-stage grinding process was carried out on the observable surface, and finally it was polished with a diamond disc (MD-Piano, DiaPro Allegro and MD-Dac) using an automatic polishing machine (Struers TegraPol-11). Figure 3 illustrates this process.

As the total studied area must be representative of the microstructure of the sample, a minimum number of captured images were required. Based on the statistical theory of Bear and Bachmat (40), 80 images of each sample were captured (Figure 2e) at a resolution of $5 \mathrm{x}$ (equivalent to an area of $6,293,382 \mu \mathrm{m}^{2}$ ), in order to cover the widest possible range of empty spaces and larger pores. In around 100 images, higher magnification objectives were combined in order to observe the smaller pores, microcracks or other microstructural features of the sample.

With the help of digital analysis (PI) software, the optical images were binarised from colour to monochrome (see Figure 3e: clear field and Figure 3f: dark field) to give a new image that was enlarged and inverted, in which the solid zones were displayed in grey, while the pores and fissures took on a black colour (Figure 3f). This treatment facilitated the interpretation of the observable zone and the quantification of porosity, taking into account the distribution of pores by size and shape (discrimination), as well as the total percentage of closed pores, in this case by means of phase analysis. To complete the study of each sample, images taken with the PI software were reconstructed using AutoCad software as an auxiliary tool to obtain a complete view of the analysed section, thus facilitating the interpretation and quantification of the distribution and connectivity of pores in 2D. In addition, in order to obtain more representative results for the total volume of the sample, two equidistant cuts were made in the $2 \mathrm{~cm}$ cubes, meaning that a total of four $4 \mathrm{~cm}^{2}$ surfaces of each type of concrete were finally analysed.

\section{RESULTS AND DISCUSSION}

The characterisation of the porous system of all the manufactured concretes is analysed and discussed here from macroscopic, at first sight (Figure 4 to Figure 5) and microscopic points of view, using

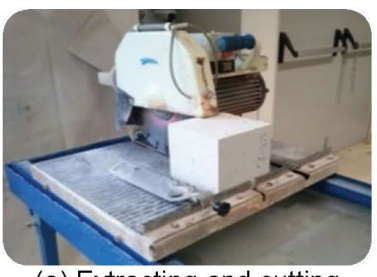

(a) Extracting and cutting (samples)

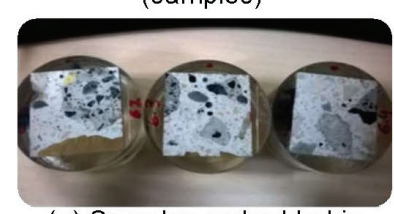

(e) Samples embedded in epoxy resin and polished

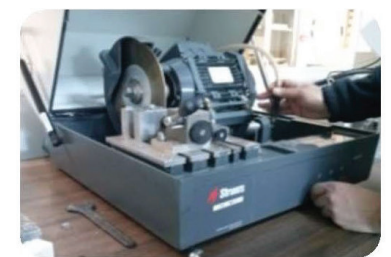

(b) Extracting and cutting (small samples, $2 \mathrm{~cm}$ cubes)

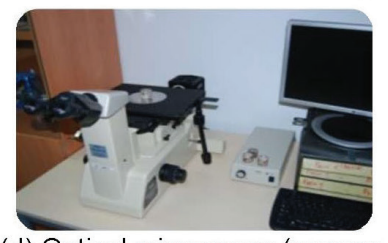

(d) Optical microscope (camera $7 \mathrm{Mp}$ ) and $\mathrm{PI}$ software

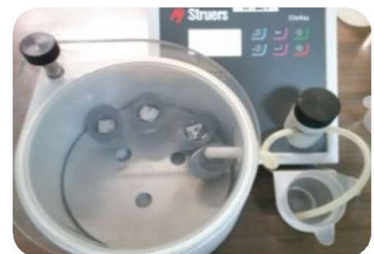

(c) Removal of air bubbles and vacuum impregnation

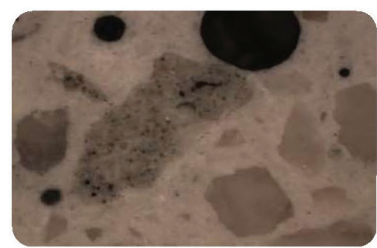

(e) Clear field image with parallel nicols

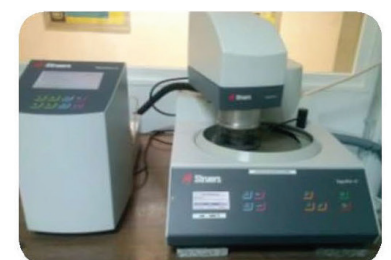

(d) Smooting and polishing

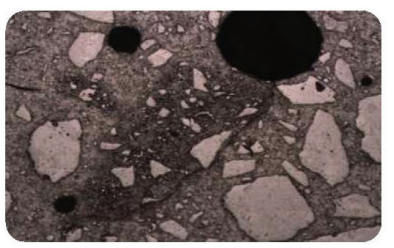

(f) Dark field image with crossed nicols

FIGURE 3. Preparation process of concrete samples for optical microscopy analysis. 


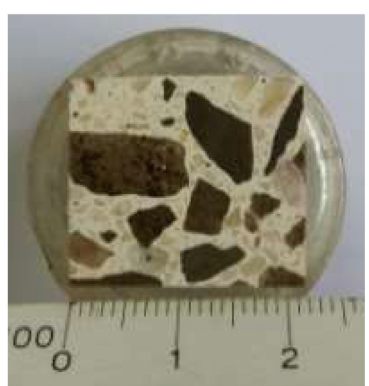

(a) N-Series C

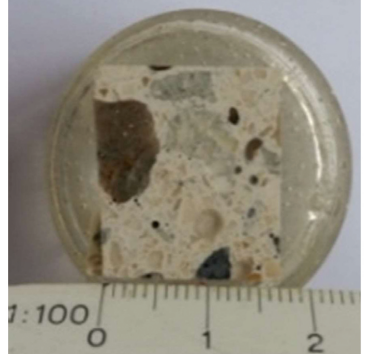

(e) R-Series 3
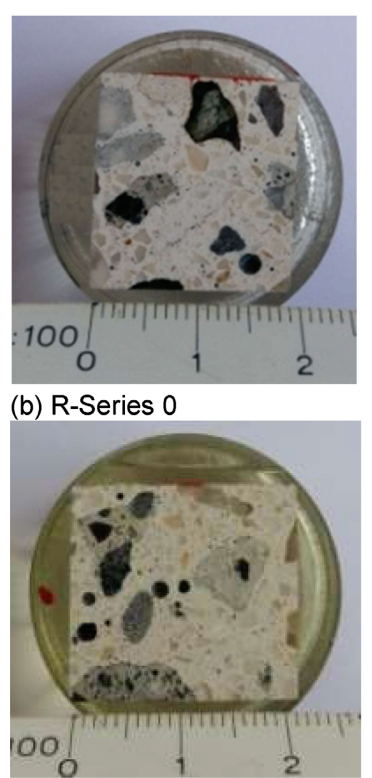

(f) R-Series 4
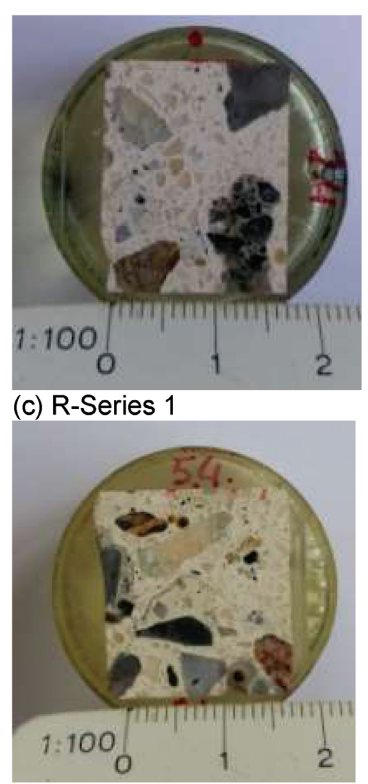

(g) R-Series 5

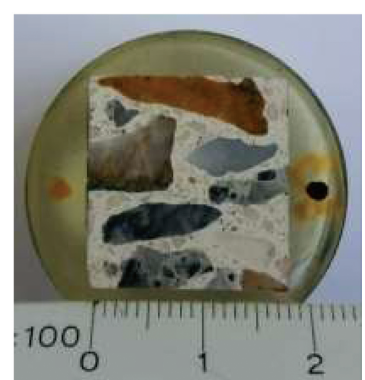

(d) R-Series 2

FIgURE 4. Subsamples of each type of manufactured concrete, embedded in epoxy resin and polished, on a scale of 1:100.

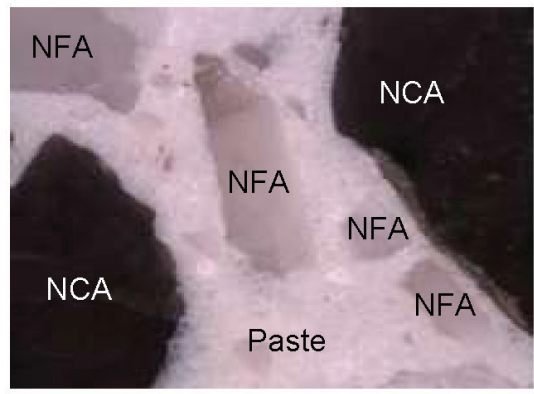

(a) NA particles (N-Series C)

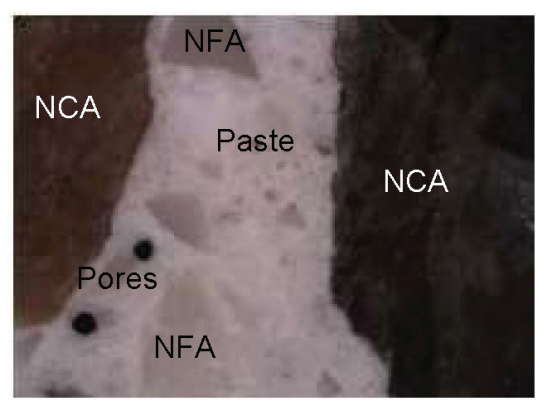

(b) NA particles (Ru) in RAC

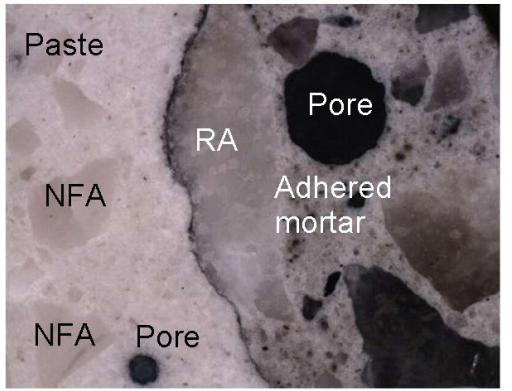

(c) RCA with adhered mortar (Rc) pre-soaked

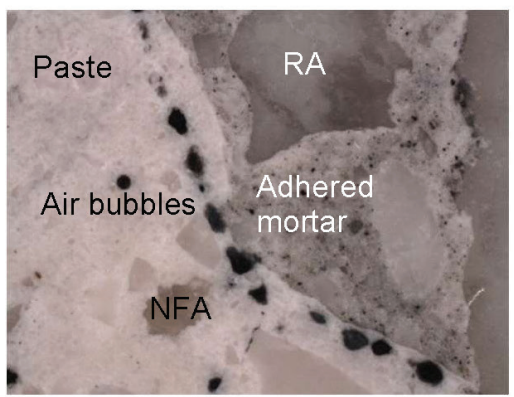

(d) RCA with adhered mortar (Rc) pre-soaked with little water or non-presoaked

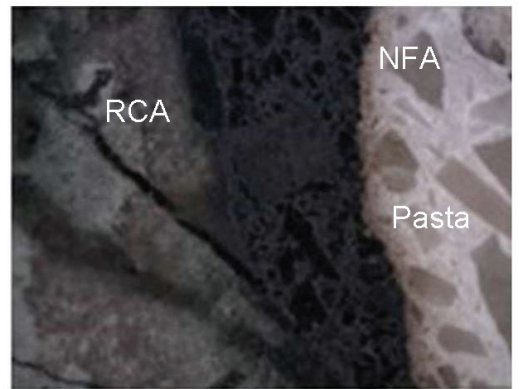

(e) RCA with bituminous material (Ra)

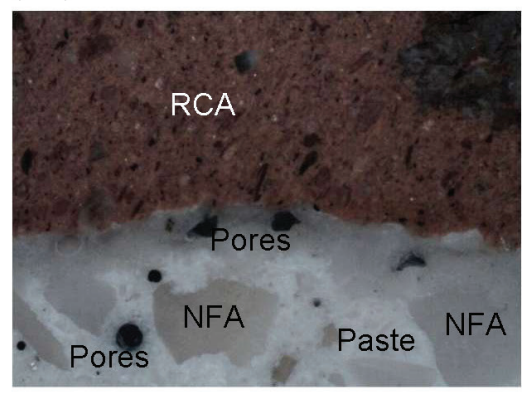

(f) RCA of ceramic nature (Rb)

FIGURE 5. Example of aggregate particles with different natures present in (a) natural concrete and (b-f) the recycled concretes manufactured in this study ( $5 \mathrm{x}$ with flat polarised light).

direct observation via optical microscopy (Figure 6 to Figure 9). Table 2 and Figure 10 to Figure 11 show the quantitative results of porosity analysis and pore distribution by size and shape.

\subsection{Macroscopic level}

Figure 4 shows an example of some subsamples, embedded in resin, of the concretes manufactured 


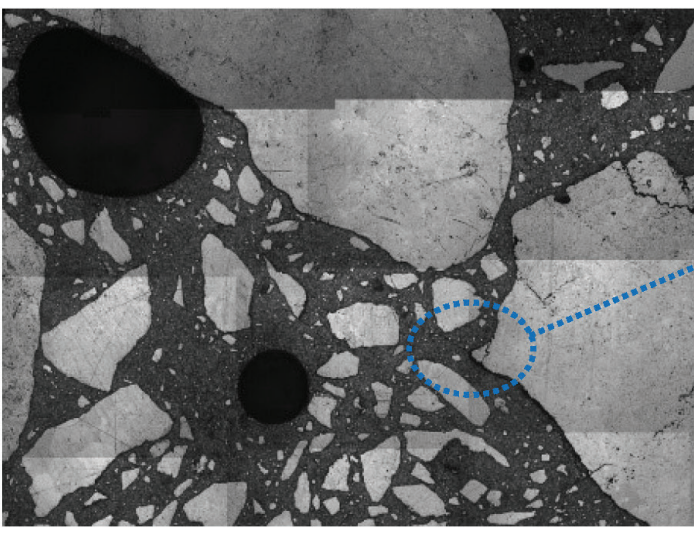

(a) Set of 9 images, equivalent to an $56 \mathrm{~mm}^{2}$ area; large pore radius approx. $1.25 \mathrm{~mm}$ and the small of $0.42 \mathrm{~mm}$, at $5 \mathrm{x}$

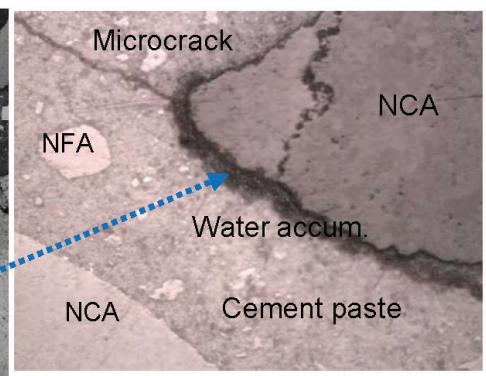

(b) Accumulation of water under NA (30-35 $\mu \mathrm{m})$ and crack in the paste $(8$ $\mu \mathrm{m})$, at $20 \mathrm{x}$

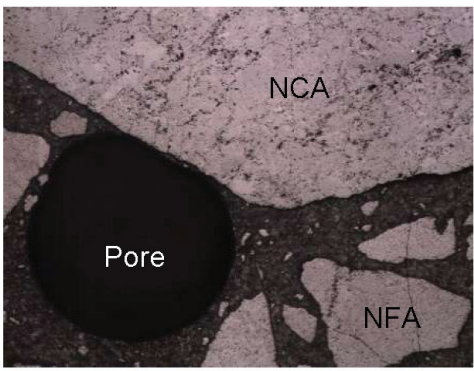

(d) Porosity by exudation $(0.45 \mathrm{~mm})$ below the surface of the NCA, at $5 x$

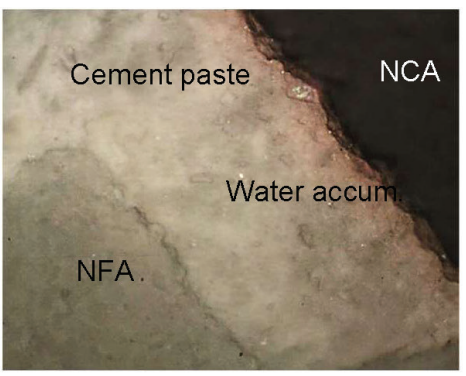

(c) Discontinuity at the pasteaggregate interface by accumulation of water $(5 \mu \mathrm{m})$, at $100 \mathrm{x}$

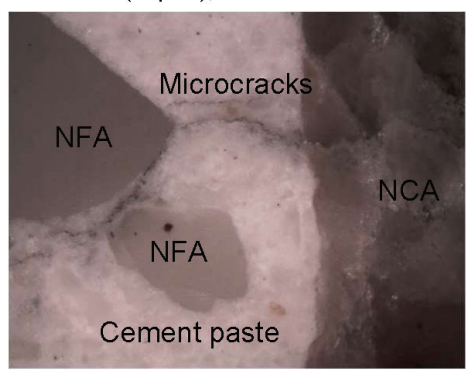

(e) Microcracks through and around the aggregates, approx. $8 \mu \mathrm{m}$. (without resin), at $20 \times$ (with parallel nicols)

Figure 6. Image analysis of $\mathrm{N}-$ Series $\mathrm{C}$ concrete samples, with polarised light and crossed nicols.

TABLE 2. Quantitative results obtained from image analysis (mean values).

\begin{tabular}{llccccccc}
\hline Property & & N-Series C & R-Series 0 & R-Series 1 & R-Series 2 & R-Series 3 & R-Series 4 & R-Series 5 \\
\hline Porosity (\%) & & 5.4 & 8.3 & 9.6 & 10.8 & 11.0 & 10.0 & 7.8 \\
Distribution by & $1-10 \mu \mathrm{m}$ & 2.38 & 11.05 & 1.33 & 4.43 & 10.42 & 17.16 & 0.76 \\
pore size, radius & $10-100 \mu \mathrm{m}$ & 88.62 & 79.99 & 79.88 & 91.08 & 76.81 & 75.62 & 79.11 \\
$(\%)$ & 8.60 & 8.95 & 18.71 & 4.49 & 12.65 & 7.16 & 19.84 \\
& $100-1000 \mu \mathrm{m}$ & 0.39 & 0.01 & 0.09 & 0.00 & 0.12 & 0.06 & 0.29 \\
& $>1000 \mu \mathrm{m}$ & 24.51 & 23.56 & 34.27 & 32.11 & 25.94 & 28.83 & 19.75 \\
Distribution & Irregular (0-0.125) & 68.57 & 60.69 & 62.94 & 62.21 & 65.90 & 62.20 & 72.29 \\
by pore shape, & Elliptical (0.125-0.8) & 6.92 & 15.75 & 2.79 & 5.67 & 8.16 & 8.97 & 7.96 \\
circularity * \%) & Circular (0.8-1) & 6.97 & & & &
\end{tabular}

(*) Parameter referring to the form factor obtained by image analysis software (28)

according to the pre-soaking study (22), both with NA and with RCA and NFA. The figure shows that at a macroscopic level, the aggregate particles, with mostly elongated shapes, are dispersed in the white cement matrix. Likewise, the heterogeneity of the RCAs can be observed; these show different tonality depending on their nature and composition, for example RCA with mortar adhering to its surface (Figure 5c, d), aggregate of asphalt (Figure 5e) or ceramic origin (Figure 5f), and even untreated aggregate particles or natural stone of a different nature within the RAC (Figure 5d).

\subsection{Microscopic level}

The microstructure of the interfacial zone varies depending on the type of cement, the nature of the aggregates and the moisture present during the dosing process, among other factors (27). According to the literature, there are approximately the same number of failed interface cases in a conventional concrete as in a recycled one $(9,41)$; however, given the higher water absorption capacity of RA compared to NA, it becomes evident that the creation of an effective interface is less likely. Thus, the behaviour 
observed in an analysis of the union of the aggregates, both natural (Figure 5a) and recycled with adhered mortar (Figure 5b-f), with the new cement paste fundamentally depends on their moisture state and water absorption, and on their nature. This is due to the fact that the excess water in the aggregate causes it to move towards the paste, generating a union characterised by being more porous.

On the other hand, if the aggregate is dry, it absorbs part of the water from the mixture, and in turn releases the air occluded inside its pores. This is distributed around the surface of the mortar adhering to the aggregate (isolated bubbles), since the interfacial bond is stronger in terms of its resistance (Figure 5d). In the particular case of the aggregate with asphalt (Figure 5e) covered with an impermeable bitumen film $(6-9 \mu \mathrm{m})$, this generated an ineffective aggregate-paste bond, giving rise to an interfacial bond that was porous and less dense than the rest of the matrix. Finally, the ceramic aggregate (Figure 5f), being more porous, behaved in a similar way as if it had been used in the dry state. These observations agree somewhat with those obtained in other studies $(9,24,27,42)$.

In view of the above, the importance of the humidity state of the RA in the formation of the microstructure of the manufactured concrete containing it makes it necessary to analyse its internal structure in greater detail in relation to the presoaking method used, and to better understand its mechanical behaviour.

For this purpose, the most important qualitative aspects (aggregate-paste/mortar bonds, porosity, fissures and particle packing and distribution) of each of the evaluated concretes were analysed after a digital analysis was carried out on the images captured with the optical microscope (Figure 6 and Figure 9). The reference concretes, N-Series C and R-Series 0 (manufactured with NA and with non-pre-soaked RA, respectively), and the rest of recycled concretes, R-Series 1 to R-Series 5 (manufactured with RA presoaked) were analysed separately, and then grouped according to the similarities observed in each of the pre-soaking methods studied.

Finally, it analysed the quantitative aspects obtained, for which the average values are summarised in Table 2; these included the 2D porosity of the subsamples used (four for each type of concrete (Figure 10), and the distribution of the percentage of pores as a function of their size and shape.

\subsubsection{Microstructure of concrete containing $N A(N$-Series $C)$}

In natural concrete (Figure 6), the discontinuity between the NA and the cement paste (Figure 6a, b), stands out, sometimes marked by the accumulation of surface water in the lower zone of the particles of the larger aggregate (Figure 6b-c); this indicates a point of weakness in the aggregate-paste contact zone (water band surrounding the aggregate with a maximum thickness of $35 \mu \mathrm{m}$ ). Although this area is the most vulnerable in conventional concrete (14), its quality will also depend on the surface characteristics of the particles of the granular material such as its texture, irregularity and porosity (43) or on the degree of exudation of the fresh concrete $(9,12)$.

The porosity observed in natural concrete is generally isolated, and is randomly distributed through the cement paste, corresponding to the occluded air (Figure 6a, d); however, the formation of air pores produced during the operations of mixing and compacting the concrete (28) and trapped under aggregates of more than $1 \mathrm{~mm}^{2}$ of irregularly shaped surface (Figure 6a) can also be observed.

Similarly, the images show the presence of simple and irregular cracks with an average width of about $8 \mu \mathrm{m}$ at the weakest points, such as pores (Figure 6b). These irregularities are also observed in the form of isolated cracks, which are typical of crushed aggregate (Figure 6b,e). These cracks pass through the paste until they find denser areas, possibly generated during hardening of the concrete.

\subsubsection{Microstructure of recycled concrete without pre-soaking ( $R$-Series 0$)$}

The internal structure of the R-Series 0 concrete is shown in Figure 7. In this case, the formation of small bubbles of air trapped at an average distance of 150-200 $\mu \mathrm{m}$ from the larger coarse aggregates (Figure 7a-c) is observed; the bubbles were isolated from each other (Figure 7c), although they were concentrated as an equidistant band around the adhered mortar (Figure 7b). This porosity is explained to a large extent by the lower w/c ratio in the aggregate-paste bond, since the RA was used without pre-soaking; this gave rise to a dry consistency (Table 2), therefore absorbing much of the water in the mixture and in turn releasing the air trapped inside.

The formation of other types of pores is also observed; these are randomly distributed throughout the cement matrix, and are of variable size and circular morphology (Figure 7e). In addition, there is the presence, in specific areas, of water accumulated in the union between mortar and paste, as well as in the RCA-paste interface (indicated in Figure $7 \mathrm{~d}$ ), and this gives rise to a minimum discontinuity between the different phases present in the RAC.

In turn, it is observed that within the random arrangement of the aggregate particles within the paste, the smaller ones are aligned towards the larger ones (Figure 7d). This was observed in all the concretes analysed, and has been discussed in the literature as being a consequence of the natural packaging of the granular structure of concrete $(24,44)$. 


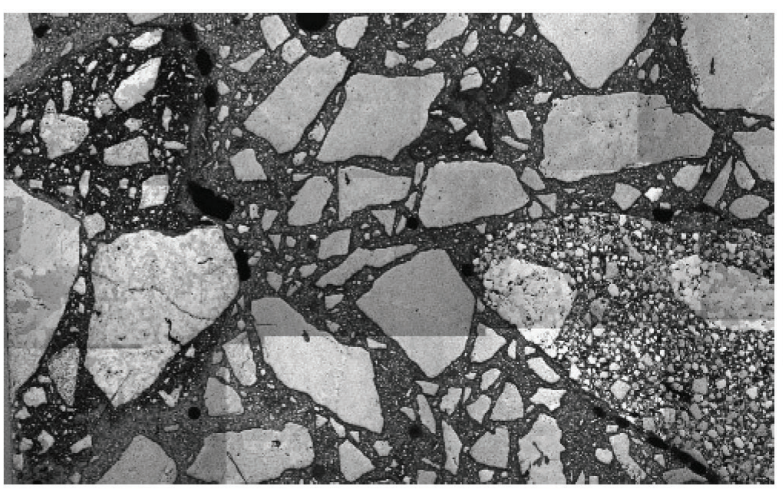

(a) Set of approximately 9 images, at $5 \times\left(\right.$ about $56 \mathrm{~mm}^{2}$ )

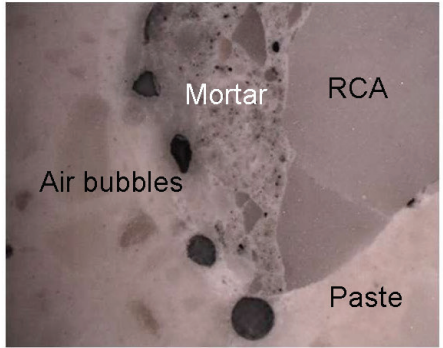

(b) Porosity in the vicinity of mortar adhered to the RCA $(90$ $\mu \mathrm{m}$ mean radius), at $5 \times$ (parallel nicols)

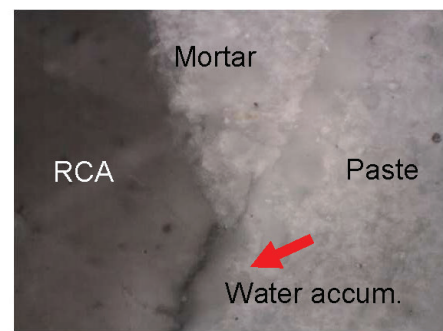

(d) Minimum discontinuity between phases due to accumulation of water in certain areas $(13 \mu \mathrm{m})$, at $100 \mathrm{x}$

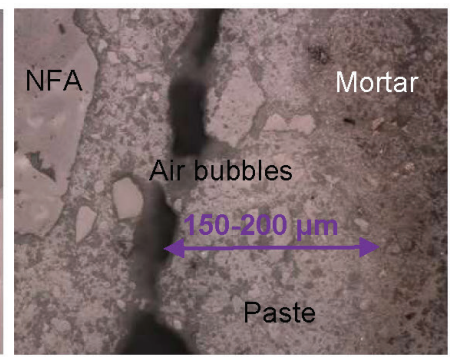

(c) Bubbles of air trapped near the aggregate $(60 \mu \mathrm{m}$ wide), but separated from its surface, at $20 \mathrm{x}$

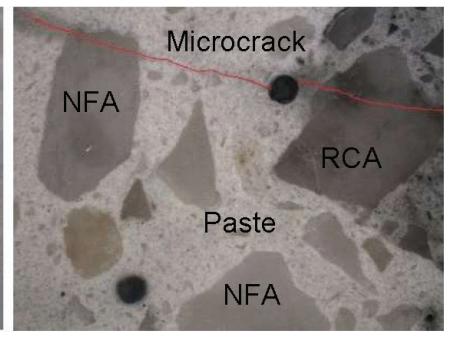

(e) Microcrak passing through $\mathrm{RCA}$ and paste $(10 \mu \mathrm{m})$ at $5 \mathrm{x}$ (parallel nicols)

FiguRE 7. Analysis of images of the sample of non-pre-soaked concrete (R-Series 0), with polarised light and crossed nicols.

The results indicate that in the particular case of concrete manufacture with RA without pre-soaked, the mechanical strength obtained $(55.54 \mathrm{MPa}$ at 28 days), similar to that of the reference concrete (55.42 MPa at 28 days, Table 1) was due to the lower effective w/c ratio caused by using non-pre-soaked RA. The existence of poorly intercommunicated porosity not located in the transition zone also contributed to the mechanical strength of this RAC. In addition, the fine detachments from the adhering mortar, the rougher surface of these aggregates and their irregularity created a good coupling of these aggregates within the cement matrix, and consequently the creation of a more homogeneous and dense microstructure. This result is corroborated by taking into account that the load transfer mechanism in concrete depends on the properties of the existing contact surfaces between its constituents (aggregates, cement matrix and transition zones) $(41,45)$. In the specific case of $\mathrm{R}$-Series 0 concrete, the union between the non-pre-soaked RA and the paste is very effective.

Finally, cracks are generally observed in RACs, since they are inherent in granular material processed by crushing, regardless of the pre-soaking method used $(23,46,47)$. However, their presence is particularly frequent at the most fragile points of the RA, with variable thicknesses and lengths that depend on the scale of observation used. The cracks already existing inside the RA generally started in the mortar-aggregate ITZ when the original concrete was subjected to loading (48), and their propagation may extend from the interfacial zone to more solid regions, passing through all the phases of the material, as shown in Figure 7e.

\subsubsection{Microstructure of $R$-Series $1, R$-Series 2 and $R$-Series 4 pre-soaked recycled concrete}

The analysis of the porous structure of R-Series $1(100 \%$ pre-soaking water and $8.9 \%$ total water), R-Series $2(50 \%$ pre-soaking water and $9.1 \%$ total water), and R-Series 4 (70\% pre-soaking water and $8.9 \%$ total water), concretes is very similar (Figure 8), and highlights the porosity associated with the accumulation of water on the surface of the aggregates, with a thickness of between $7 \mu \mathrm{m}$ and $55 \mu \mathrm{m}$ (Figure 8a-c).

The higher pre-soaking water content used in these mixtures, combined with the increase in their total water (Figure 2), generated an excess of hydration water, which migrated towards the surface of the aggregates in an exudation process, causing the $w / c$ ratio in the aggregate-paste transition zone to be higher than in the rest of the matrix. This fact is observed in the interfaces characterized by their high porosity and greater width (Figure $8 b$ ) which has provided a discontinuity between phases. 


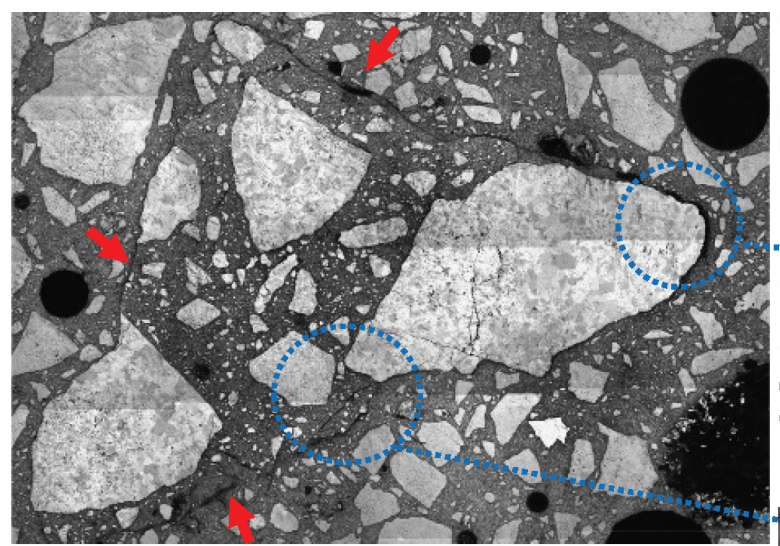

(a) Set of approximately 9 images, at $5 \times$ (about $56 \mathrm{~mm} 2$ )

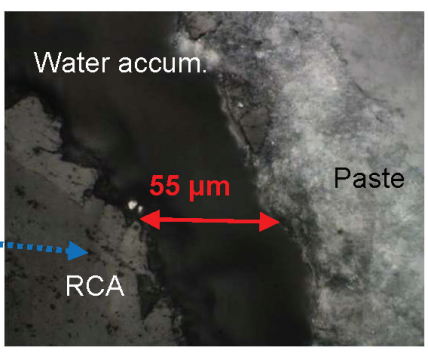

(b) RCA with water accumulation on its surface, at $100 \mathrm{x}$

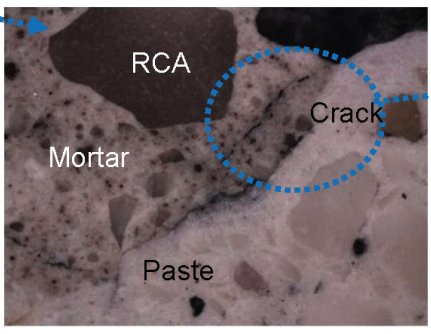

(d) Cracks that cross the RCA and continue through the paste$\mathrm{RCA}$ interface, at $5 \mathrm{x}$ (parallel nicols)

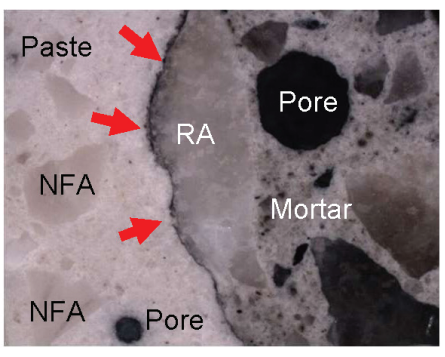

(c) Discontinuity at the interface by water adhered to the surface of the ARG $(20 \mu \mathrm{m})$, at $5 \mathrm{x}$ (parallel nicols)

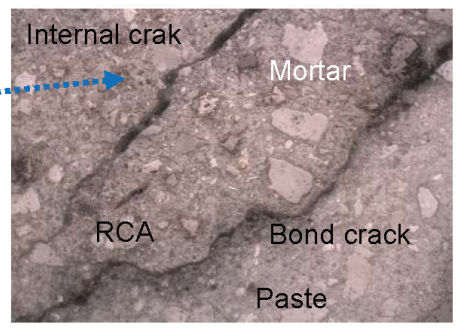

(e) Internal crack (15 $\mu \mathrm{m})$ and bond crack between aggregate and paste $(7 \mu \mathrm{m})$, at $20 \mathrm{x}$

FIGURE 8. Analysis of images of R-Series 1, R-Series 2 and R-Series 4 concretes with polarized light and crossed nicols.

Likewise, the porosity present in these concretes is also formed by air voids distributed by the paste and those of the recycled material, as shown in the Figure 8a, c.

In relation to the shape of the aggregates, as mentioned above, it is observed that the RCA have a less angular shape compared to natural ones, due to the greater friability of the former caused by the detachment of a certain amount of fines; this characteristic, together with the better coupling of the particles (Figure $8 a$ ), provided greater compactness to the whole (49). This fact, in a way, offset the weakness in the interfacial joints, which has been reflected in its resistance to 28 days, with decreases with respect to the value obtained in the reference concrete $(55.42$ $\mathrm{MPa})$ of $7 \%$ for the pre-soaked R-Series 1 (51.75 $\mathrm{MPa}$ ) and $16 \%$ for R-Series $2(46.67 \mathrm{MPa})$ and R-Series 4 (46.09 MPa) concretes.

Lastly, the fissures observed in these concretes, as in the previous case, belong in their great majority to those generated inside the RA. Still others formed during the concrete hardening process (Figure 8d,e) because of the difference between the modulus of elasticity of the components at the interface, resulting in higher tangential, radial and/or shear stresses in this zone $(50,51)$. It is for this reason that during the compression rupture test the RAC breaks, more frequently, by the internal cracks of the RA, while the natural one can do it also by the ITZ between aggregate and paste.

\subsubsection{Microstructure of $R$-Series 3 and $R$-Series 5 pre-soaked recycled concrete}

Figure 9 shows the internal structure of R-Series $3(12 \%$ pre-soaking water and $9.1 \%$ total water), and R-Series $5(80 \%$ pre-soaking water and $8.0 \%$ total water), concretes, which is characterized by the presence of a certain amount of air bubbles around the RCAs (Figure 9a-c), aligned as an equidistant band around their surface, with an average value of $100 \mu \mathrm{m}$ (Figure 9c), although less frequently than in non-pre-soaked concrete (R-Series 0$)$.

This type of porosity is caused, in the case of the $\mathrm{R}$-Series 3, because the aggregates were pre-soaked with only $12 \%$ of the total water for 10 minutes (interfacial bond with low w/c ratio), which resulted in a plastic consistency (Table 1). While this phenomenon occurs in the R-Series 5 because the RCA were pre-soaked with $80 \%$ of the mixing water, but without adding additional water to the mixture (8.0\% total water), thus obtaining a dry consistency (Table 1).

It is also observed the accumulation of a small layer of water in random areas of the surface of some aggregates (Figure 9d,e), which gave rise to a minimum discontinuity between the cement paste and the adhered mortar; even pores distributed throughout the matrix that corresponds to the air occluded generated during the mixing and pouring of the concrete, whose shape tends to become 


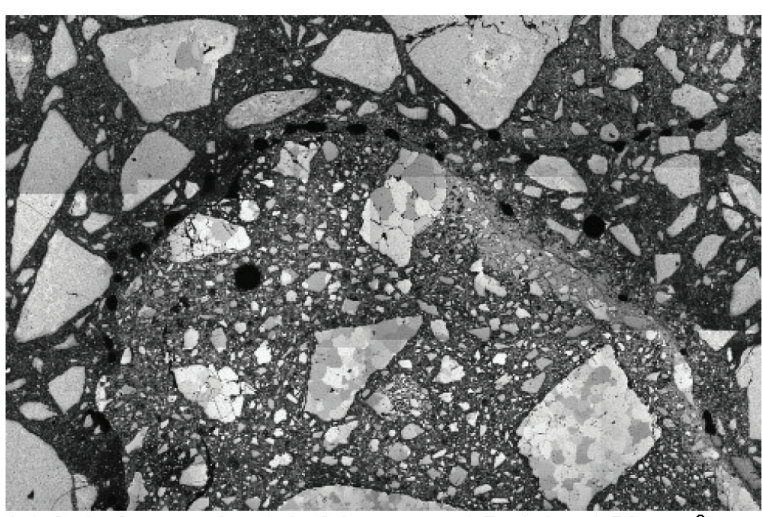

(a) Set of approximately 9 images, at $5 \times$ (about $56 \mathrm{~mm}^{2}$ )

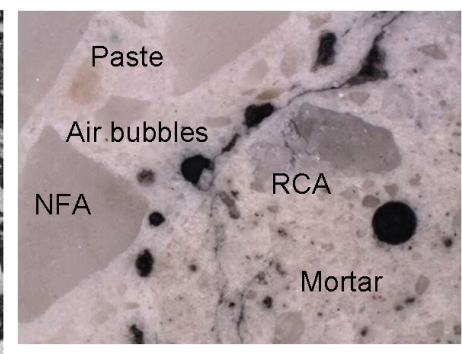

(b) RCA with adhering mortar (white cement); surface and internal porosity and fissure through mortar, $5 x$ (parallel nicols)

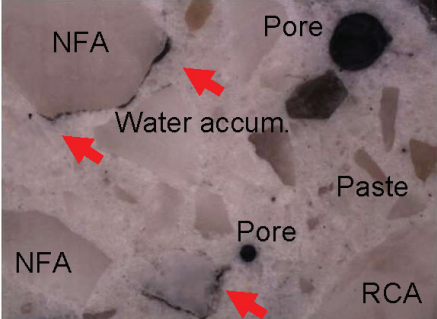

(d) Discontinuity in the interface by accumulation of water on the surface of the RCA (parallel niches), at $5 x$

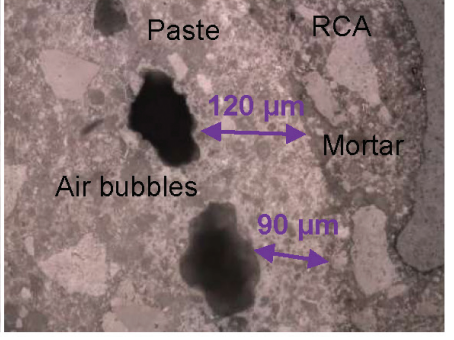

(c) Air bubbles trapped near $\mathrm{RCA}$; minimal discontinuity mortar and paste, at $20 x$

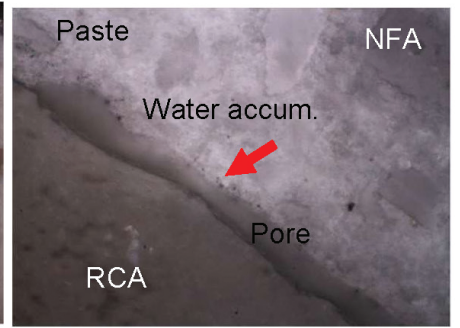

(e) NFA with adhering surface water $(11 \mu \mathrm{m})$, at $100 \mathrm{x}$

FIgURE 9. Analysis of images of R-Series 3 and R-Series 5 concretes, with polarized light and crossed nicols.

less spherical as its diameter increases (Figure 9d), or those generated inside the recycled mortar (Figure 9a, b). In spite of this, the porous structure, together with other qualities of the aforementioned $\mathrm{RA}$, gives rise to adequate mechanical behaviour of these concretes that is similar to concrete manufactured with NA (55.42 MPa, Table 1) in the case of the pre-soaked R-Series 5 series, or with a decrease of only $9 \%$ in the R-Series 3 concrete.

In terms of cracks and coupling of aggregate particles, the images show insignificant changes with respect to what was observed in the other recycled concretes; therefore, these qualitative aspects of concrete are not conditioned by the pre-soaking method used.

\subsection{Quantitative analysis}

\subsubsection{Porosity}

The average percentages of pores quantified from the analysis of the four subsamples studied are presented in Table 2. This shows that the porosity of natural concrete $(5.4 \%)$ is lower than that of RACs, which are mainly concentrated between sizes of 10 and $100 \mu \mathrm{m}(88.62 \%)$ and whose morphology is presented in mostly elliptical forms $(68.57 \%)$.

Of the values obtained in recycled concretes, the R-Series 0 (RA without pre-soaked) series shows one of the lowest porosities $(8.3 \%)$, with pores that are mostly between sizes 10 and $100 \mu \mathrm{m}(80 \%)$ and have elliptical shapes $(60.69 \%)$, as shown in Figure $7 \mathrm{~b}$ and $\mathrm{c}$. In the case of the pre-soaked recycled concretes, the percentage of pores measured varied from $7.8 \%$ (R-Series 5 , with $8 \%$ total water) to $11 \%$ (R-Series 3, with 9.1\% total water), with both irregular (between 20\% and 35\%) and elliptical (above $60 \%$ ) shapes. Their distribution is also concentrated in the range $10-100 \mu \mathrm{m}$ (approximately $80 \%$ ), including both the pores formed inside the cement matrix and those inherent in the RA.

Figure 10 compares the data obtained on the porosity of each of the concretes tested, together with the values of the variables that differentiate the pre-soaking method applied in each case (Table 1) and the deviation obtained. The results presented show the data of the reference series (N-Series $\mathrm{C}$ and R-Series 0) followed by the data of the pre-soaking series (R-Series 1 to R-Series 5), ordered from the lowest value to the highest, to facilitate an analysis of the influence of these variables on the results.

A greater content of pores can be observed in the RAC compared to that obtained in the reference concrete $(5.4 \%)$, with increases ranging from $44 \%$ to $54 \%$ for R-Series 5 (pre-soaked, but without additional water) and R-Series 0 (without pre-soaking) concretes, respectively, to more than double for the remainder of the pre-soaked concretes (R-Series 1 to $\mathrm{R}$-Series 4). These porosities increase with the total water content, thus confirming the influence of the 


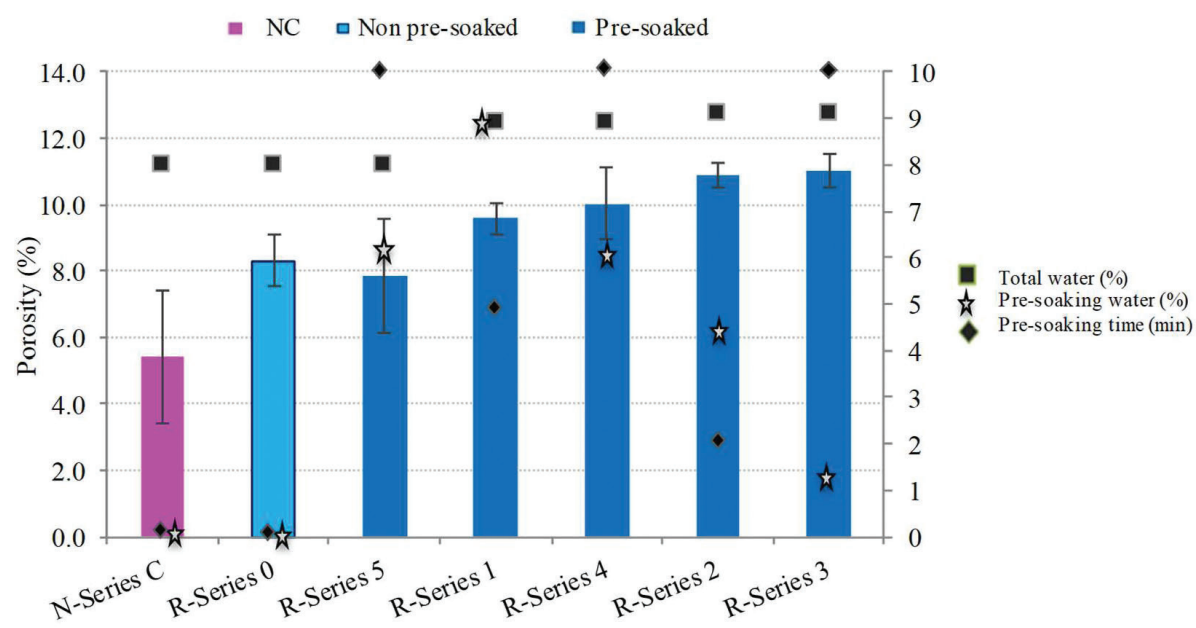

Figure 10. Porosity of concretes observed by optical microscopy.

increase in the w/c ratio on the porosity obtained; results that have also been obtained by other authors (25). This is confirmed for the concrete series $\mathrm{R}$-Series 1 to $\mathrm{R}$-Series 4 , in which a greater accumulation of water was observed, after image analysis, on the surface of the pre-soaked aggregates, and a worsening of their mechanical behaviour. In relation to the rest of the variables analysed (water and pre-soaking time), Figure 10 shows the weak influence of these variables on the results obtained.

\subsubsection{Pore distribution by size and shape.}

Figure 11a shows that the distribution of pores in the concretes evaluated here shows a similar trend in all of them, regardless of the type of aggregate and pre-soaking method used.

The maximum range of pores is concentrated between 10 and $100 \mu \mathrm{m}$, with a maximum value of $91 \%$ (R-Series 2, with $50 \%$ pre-soaking water and $9.1 \%$ total water) and a minimum of $75 \%$ (R-Series 4 , with $70 \%$ pre-soaking water and $8.9 \%$ total water). These correspond to the porosity generated in the cement matrix (both new and old), which is usually spherical and arises from air bubbles that have become trapped during mixing and compacting of the concrete, with a random distribution throughout the material. In addition, small bubbles are generated in the vicinity of the RCA (Figure $7 \mathrm{~b}$, Figure 9c and Figure 8b), due to the large difference in humidity between the aggregate and the paste, although due to the fact that these are closed pore systems, their presence does not intervene in transport phenomena such as permeability or capillarity (28).

The pore content quantified as sizes greater than $100 \mu \mathrm{m}$ (up to $>1000 \mu \mathrm{m}$ ), is less significant, with percentages ranging from $7 \%$ (R-Series 4 , with $70 \%$ pre-soaking water and $8.9 \%$ total water) to $20 \%$ (R-Series 5, with $80 \%$ pre-soaking water and $8 \%$ total water). This range includes those pores that were retained between or under the larger aggregates by the same exudation of water, and which left these elliptical shaped voids in their place on evaporating (Figure 6a, Figure 7d, Figure 8d and Figure 9a). Considering that this porosity negatively affects the mechanical resistance due to its large size, and plays an important role in frost resistance (28), its lower content will reduce the degradation of the concretes studied.

Lastly, The percentage of pores with the smallest sizes $(1-10 \mu \mathrm{m})$ is also unrepresentative, with values between 1\% (R-Series 5) and 17\% (R-Series 4); this is related to capillary pores of medium size, whose influence on permeability and resistance is expected to be minimal due to their low proportion (28).

In terms of morphology of the pores (Figure 11b), the data obtained show the tendency of these to form elliptical shapes, independently of the type of concrete analysed, with a minimum value of $60 \%$ (R-Series 0 ) and a maximum value of 72\% (R-Series 5 ) for the series without pre-soaking and with presoaking but without additional water, respectively.

According to the images analysed, this porosity corresponds to the air bubbles and pores trapped inside the hydrated cement paste. These have variable radius (Figure 7c, Figure 8d and Figure 9c), and occupy the intergranular spaces in the matrix with little or no interconnection between them, thus reducing their influence on permeability (52).

The percentage of irregular pores obtained to a certain extent represents the accumulation of water in the interfacial zones. This is observable in practically all types of concrete, and has a minimum value of close to $20 \%$ in R-Series 5 concrete and a maximum of $34 \%$ in R-Series 1 (corresponding to the 


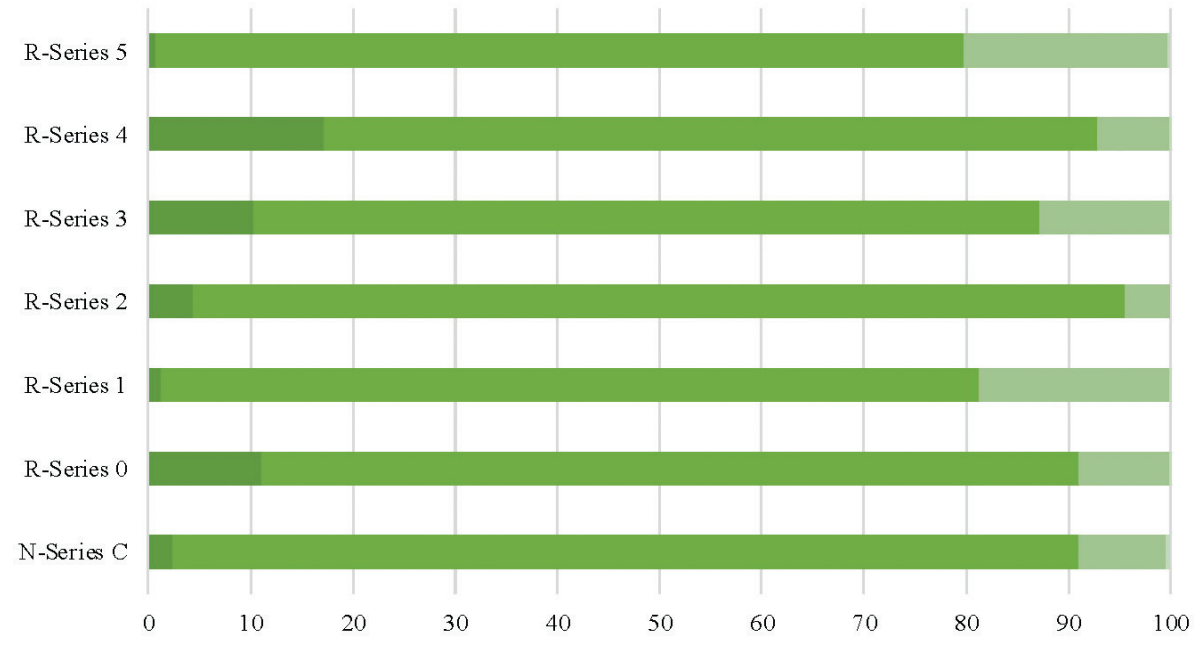

(a)

$\square 1-10 \mu \mathrm{m} \quad \square 10-100 \mu \mathrm{m} \quad \square 100-1000 \mu \mathrm{m} \quad \square>1000 \mu \mathrm{m}$

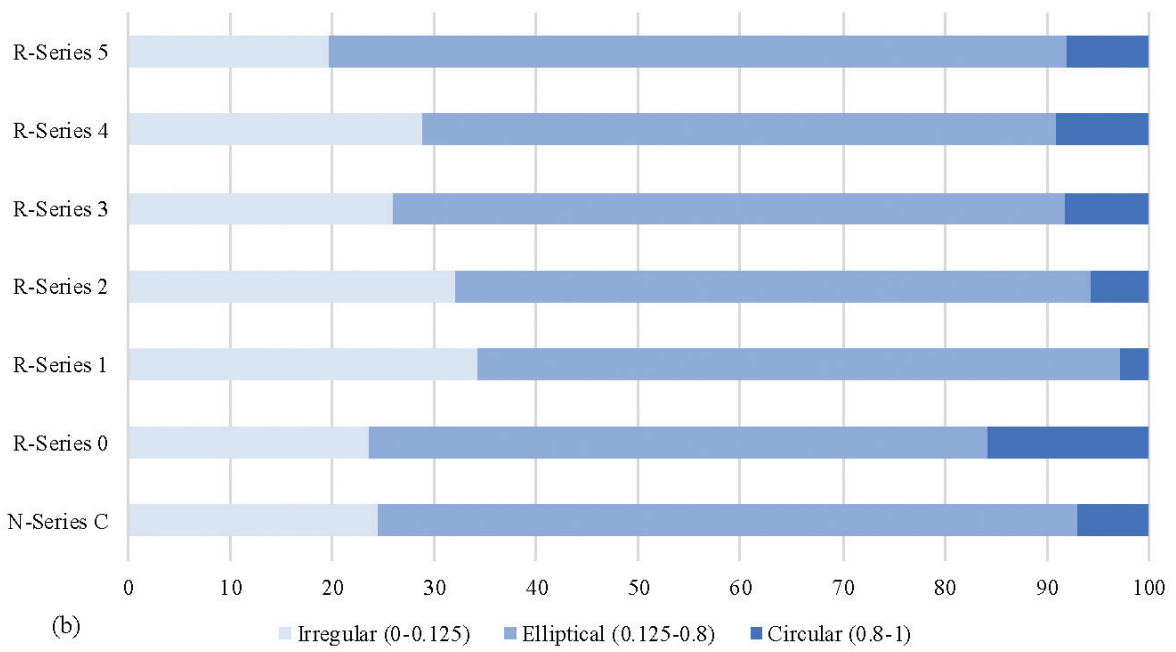

FIGURE 11. Distribution by pore size (\%) according to radius (a) and shape (b).

pre-soaked series with the lowest w/c ratio and the highest water content used for pre-soaking of the $\mathrm{RA}$, respectively).

Finally, circular pores make up the smallest percentage, between 3\% (R-Series 1) and 16\% (R-Series 0 ); these are formed from spherical air bubbles with a radius greater than $10 \mu \mathrm{m}$. These results contrast with those previously obtained via image analysis.

\section{CONCLUSIONS}

The use of RA in concrete affects its microstructure, as a consequence of the greater or lesser amount of water added to the mixture; therefore, it is necessary to analyse different pre-soaking methods to determine which method is the most effective for the producing non-structural concrete on an industrial scale. The main conclusions obtained in this research are the following:
- The percentage of pores in the $\mathrm{RC}$ increases if the total water content rises; therefore, the method proposed in this research (Method 5), which consists of pre-soaking the recycled aggregate with the water used for mixing but without adding additional water to the mixture, thus, not constituting an increase in the total water content, is the one that presented the lowest percentage of pores compared to the value obtained in the rest of the concretes made with RA.

- In the microstructure, analysed by optical microscope images, an interfacial bond of more porous RA cement paste is observed in concretes produced with pre-soaking methods that increase their total water content $(\mathrm{w} / \mathrm{c}$ ratio greater than 0.48), which was reflected in its greater porosity and a reduction in its resistance to compression at 28 days. 
- When the w/c ratio (0.48) remained constant, both with the pre-soaking and without the RCA pre-soaking, concrete with low working capacity was obtained but an aggregate-paste bond was generated that was stronger due to poor interconnections in the pores formed around the RCA. Despite their higher porosity (which was slightly higher than that of natural concrete but lower than that of previously soaked concretes), concretes made with Method 5 and Method 0 led to excellent improvements in their compressive strength, which will reduce its influence on concrete durability.

Due to the complexity and higher costs involved in implementing pre-soaking techniques on an industrial scale, the results suggest that the most optimal pre-soaking method for the industrial-scale production of non-structural RACs is the one without presoaking (Method 0). This implies the incorporation of an optimal dose of superplasticising additives, to increase their workability and their docility without compromising their microstructural and mechanical development.

The information obtained in this research contributes significantly to a better understanding of the structure of the porous system of recycled concretes that are manufactured according to different methods.

\section{ACKNOWLEDGEMENTS}

We would like to thank the Department of Building Construction of Granada University and the research group "Materiales de Construcción, Restauración y Dinámica de Suelos" (TEP-942) of the Andalusian Research Plan.

\section{REFERENCES}

1. Comisión Europea (2014) COM 445. Comunicación de la Comisión al Parlamento Europeo, al Consejo, al Comité Económico y Social Europeo y al Comité de las Regiones. Oportunidades para un uso más eficiente de los recursos en el sector de la construcción. Comisión Europea, Bruselas, (2014).

2. Comisión Europea (2015) COM 614. Comunicación de la Comisión al Parlamento Europeo, al Consejo, al Comité Económico y Social Europeo y al Comité de las Regiones. Cerrar el círculo: Un plan de acción de la UE para la economía circular (COM 614). Comisión Europea, Bruselas, (2014).

3. UEPG (2017) European aggregates association. A sustainable industry for a sustainable Europe. Annual Review 20162017. Union Européenne des Producteurs de Granulats. Retreived from http://www.uepg.eu/uploads/Modules/ Publications/uepg-ar2016-17_32pages_v10_18122017_ pbp_small.PDF.

4. Tam, V.W.Y.; Soomro, M.; Evangelista, A.C.J. (2018) A review of recycled aggregate in concrete applications (2000-2017). Constr. Build. Mater. 172, 272-292. https:// doi.org/10.1016/j.conbuildmat.2018.03.240.

5. Ministerio de Fomento (2008) EHE-08. Instrucción de Hormigón Estructual. BOE. 203, 35176-35178.
6. Poon, C.-S.; Shui, Z.; Lam, L.; Fok, H.; Kou, S.-C. (2004) Influence of moisture states of natural and recycled aggregates on the slump and compressive strength of concrete. Cem. Concr. Res. 34 [1], 31-36. https://doi.org/10.1016/ S0008-8846(03)00186-8.

7. Etxeberria, M.; Vázquez-Ramonich, E.; Marí, A.R.; Barra de Oliveira, M. (2007) Influence of amount of recycled coarse aggregates and production process on properties of recycled aggregate concrete. Cem. Concr. Res. 37 [5], 735742. https://doi.org/10.1016/j.cemconres.2007.02.002.

8. Thomas García, C.; Setién, J.; Polanco Madrazo, J.A.; Cimentada, A.I.; Medina, C. (2018) Influence of curing conditions on recycled aggregate concrete. Constr. Build. Mater. 172, 618-625. https://doi.org/10.1016/j. conbuildmat.2018.04.009.

9. Etxeberria, M. (2004) Experimental study on microstructure and structural behaviour of recycled aggregate concrete. Univ. Politec. Catalunya. 242. http://hdl.handle. net $/ 2117 / 93470$

10. Li, W.; Xiao, J.; Sun, Z.; Kawashima, S.; Shah, S.P. (2012) Interfacial transition zones in recycled aggregate concrete with different mixing approaches. Constr. Build. Mater. 35, 1045-1055. https://doi.org/10.1016/j. conbuildmat.2012.06.022.

11. Puertas Maroto, F.; Blanco Varela, M.T.; Palomo Sánchez, A. (1989) Microestructura del hormigón: influencia sobre sus propiedades. Monografia ${ }^{\circ}$ 398, Consejo Superior de Investigaciones Científicas.

12. Maso, J.C. (1996) Interfacial Transition Zone in Concrete: state-of-the-art report. RILEM Techical Comm. 108-ICC, Interfaces Cem. Compos. 179. https://doi. org/10.1201/9781482271560.

13. Gao, X.F.; Lo, Y.T.; Tam, C.M. (2002) Investigation of micro-cracks and microstructure of high performance lightweight aggregate concrete. Build. Environ. 37 [5], 485-489. https://doi.org/10.1016/S0360-1323(01)00051-8.

14. Etxeberria, M.; Vázquez-Ramonich, E.; Marí, A.R. (2006) Microstructure analysis of hardened recycled aggregate concrete. Mag. Concr. Res. 58 [10], 683-690. https://doi. org/10.1680/macr.2006.58.10.683.

15. Bonifazi, G.; Capobianco, G.; Serranti, S.; Eggimann, M.; Wagner, E.; Di Maio, F.; Lotfi, S. (2015) The ITZ in concrete with natural and recycled aggregates: Study of microstructures based on image and SEM analysis. In: Proc. 15th Euroseminar Microsc. Appl. to Build. Mater. 299-308. Retreived from http://resolver.tudelft.nl/uuid: b92471c4-2a8e-4643-9c59-0bca35957025.

16. Xiao, J.; Li, W.; Corr, D.J.; Shah, S.P. (2013) Effects of interfacial transition zones on the stress-strain behavior of modeled recycled aggregate concrete. Cem. Concr. Res. 52, 82-99. https://doi.org/10.1016/j.cemconres.2013.05.004

17. Duan, P.; Shui, Z.; Chen, W.; Shen, C. (2013) Enhancing microstructure and durability of concrete from ground granulated blast furnace slag and metakaolin as cement replacement materials. J. Mater. Res. Technol. 2 [1], 52-59. https://doi.org/10.1016/j.jmrt.2013.03.010.

18. Tam, V.W.Y.; Tam, C.M. (2007) Assessment of durability of recycled aggregate concrete produced by two-stage mixing approach. J. Mater. Sci. 42, 3592-3602. https://doi. org/10.1007/s10853-006-0379-y.

19. Wang, R.; Yu, N.; Li, Y. (2020) Methods for improving the microstructure of recycled concrete aggregate: A review. Constr. Build. Mater. 242, 118164. https://doi.org/10.1016/j. conbuildmat.2020.118164

20. Pelufo, M.J.; Domingo Cabo, A.; Ulloa Mayorga, V.A.; Vergara Acuña, N.N. (2009) Analysis of moisture state of recycled coarse aggregate and its influence on compression strength of the concrete. Shell Spat. Struct. IASS. [October], 2932-2940. http://hdl.handle.net/10251/6652.

21. Mefteh, H.; Kebaili, O.; Oucief, H.; Berredjem, L.; Arabi, N. (2013) Influence of moisture conditioning of recycled aggregates on the properties of fresh and hardened concrete. J. Clean. Prod. 54, 282-288. https://doi. org/10.1016/j.jclepro.2013.05.009.

22. Sánchez-Roldán, Z.; Martín-Morales, M.; ValverdePalacios, I.; Valverde-Espinosa, I.; Zamorano, M. (2016) 
Study of potential advantages of pre-soaking on the properties of pre-cast concrete made with recycled coarse aggregate. Mater. Constr. 66 [321], e076. https://doi.org/10.3989/ mc.2016.01715.

23. Tam, V.W.Y.; Gao, X.F.; Tam, C.M. (2005) Microstructural analysis of recycled aggregate concrete produced from twostage mixing approach. Cem. Concr. Res. 35 [6], 1195-1203. https://doi.org/10.1016/j.cemconres.2004.10.025.

24. Leite, M.B.; Monteiro, P.J.M. (2016) Microstructural analysis of recycled concrete using X-ray microtomography. Cem. Concr. Res. 81, 38-48. https://doi.org/10.1016/j. cemconres.2015.11.010.

25. Thomas García, C.; Setién, J.; Polanco, J.A.; de Brito, J.; Fiol, F. (2019) Micro- and macro-porosity of dry- and saturated-state recycled aggregate concrete. J. Clean. Prod. 211,932-940. https://doi.org/10.1016/j.jclepro.2018.11.243.

26. Zhang, W.; Wang, S.; Zhao, P.; Lu, L.; Cheng, X. (2019) Effect of the optimized triple mixing method on the ITZ microstructure and performance of recycled aggregate concrete. Constr. Build. Mater. 203, 601-607. https://doi. org/10.1016/j.conbuildmat.2019.01.071.

27. Sidorova, A.; Vázquez-Ramonich, E.; Barra-Bizinotto, M.; Roa-Rovira, J.J.; Jimenez-Pique, E. (2014) Study of the recycled aggregates nature's influence on the aggregate-cement paste interface and ITZ. Constr. Build. Mater. 68, 677-684. https://doi.org/10.1016/j. conbuildmat.2014.06.076.

28. Aligizaki, K.K. (2006) Pore structure of cement-based materials: testing, interpretation and requirements, Taylor \& Francis, Abingdon, England, (2006).

29. Bravo, M.; Santos Silva, A.; de Brito, J.; Evangelista, L. (2016) Microstructure of Concrete with Aggregates from Construction and Demolition Waste Recycling Plants. Microsc. Microanal. 22 [1], 149-167. https://doi. org/10.1017/S1431927615015512.

30. Bonifazi, G.; Palmieri, R.; Serranti, S. (2018) Evaluation of attached mortar on recycled concrete aggregates by hyperspectral imaging. Constr. Build. Mater. 169, 835-842. https://doi.org/10.1016/j.conbuildmat.2018.03.048.

31. Estefano De Oliveira, M.J.; Barros Oliveira, M.C. Silveira de Assis, C.; Tavares de Mattos, J. (2004) Petrographic Analysis on Recycled Aggregate-produced Concrete. In: Int RILEM Conf Use Recycl. Mater. Build. Struct. 563-570.

32. Molina, E.; Cultrone, G.; Sebastián, E.; Alonso, F.J.; Carrizo, L.; Gisbert, J.; Buj, O. (2011) The pore system of sedimentary rocks as a key factor in the durability of building materials. Eng. Geol. 118 [3-4], 110-121. https://doi. org/10.1016/j.enggeo.2011.01.008.

33. Molina, E.: Cultrone, G.; Sebastián, E.; Alonso, F.J. (2013) Evaluation of stone durability using a combination of ultrasound, mechanical and accelerated aging tests. J. Geophys. Eng. 10 [3], 035003. https://doi. org/10.1088/1742-2132/10/3/035003.

34. Abbas, A.; Fathifazl, G.; Fournier, B.; Isgor, O.B.; Zavadil, R.; Razaqpur, A.G.; Foo, S. (2009) Quantification of the residual mortar content in recycled concrete aggregates by image analysis. Mater. Charact. 60 [7], 716-728. https://doi. org/10.1016/j.matchar.2009.01.010.

35. AEN/CTN 146 (2009) EN 12620:2003+A1. Aggregate for concrete. Áridos para hormigón. AENOR, Madrid. Retreived from https://www.aenor.com/normas-y-libros/ buscador-de-normas/une?c=N0043155.

36. Agrela, F.; Sánchez de Juan, M.; Ayuso, J.; Geraldes, V.L.; Jiménez, J.R. (2011) Limiting properties in the characterisation of mixed recycled aggregates for use in the manufacture of concrete. Constr. Build. Mater. 25 [10], 3950-3955. https://doi.org/10.1016/j.conbuildmat.2011.04.027.
37. Cachim, P.B. (2009) Mechanical properties of brick aggregate concrete. Constr. Build. Mater. 23 [3], 1292-1297. https://doi.org/10.1016/j.conbuildmat.2008.07.023.

38. Mas, B.; Cladera, A.; Olmo, T. Del; Pitarch, F. (2012) Influence of the amount of mixed recycled aggregates on the properties of concrete for non-structural use. Constr. Build. Mater. 27 [1], 612-622. https://doi.org/10.1016/j. conbuildmat.2011.06.073.

39. Evangelista, L.; De Brito, J. (2007) Mechanical behaviour of concrete made with fine recycled concrete aggregates. Cem. Concr. Compos. 29 [5], 397-401. https://doi. org/10.1016/j.cemconcomp.2006.12.004.

40. Bear, J.; Bachmat, Y. (1990) Introduction to modeling of transport phenomena in porous media, Kluwer Academic Publishers, Dordrecht, Netherlands (1990), Theory Appl. Transp. Porous Media. Retreived from https://www. springer.com/gp/book/9780792305576.

41. Thomas, J.; Thaickavil, N.N.; Wilson, P.M. (2018) Strength and durability of concrete containing recycled concrete aggregates. J. Build. Eng. 19, 349-365. https://doi. org/10.1016/j.jobe.2018.05.007.

42. Huang, B.; Shu, X.; Li, G. (2005) Laboratory investigation of portland cement concrete containing recycled asphalt pavements. Cem. Concr. Res. 35 [10], 2008-2013. https:// doi.org/10.1016/j.cemconres.2005.05.002.

43. López Orozco, J.O. (2004) Porosidad del concreto. (Tesina). Universidad de San Carlos, Guatemala. Recuperado de http://biblioteca.usac.edu.gt/tesis/08/08_2394_C.pdf.

44. Valcuende, M.; Marco, E.; Parra, C.; Serna, P. (2012) Influence of limestone filler and viscosity-modifying admixture on the shrinkage of self-compacting concrete. Cem. Concr. Res. 42 [4], 583-592. https://doi.org/10.1016/j. cemconres.2012.01.001.

45. Chen, X.; Wang, G.; Dong, Q.; Zhao, X.; Wang, Y. (2020) Microscopic characterizations of pervious concrete using recycled Steel Slag Aggregate. J. Clean. Prod. 254, 120149. https://doi.org/10.1016/j.jclepro.2020.120149.

46. Nagataki, S.; Gokce, A.; Saeki, T.; Hisada, M. (2004) Assessment of recycling process induced damage sensitivity of recycled concrete aggregates. Cem. Concr. Res. 34 [6], 965-971.https://doi.org/10.1016/j.cemconres.2003.11.008.

47. Lee, G.C.; Choi, H.B. (2013) Study on interfacial transition zone properties of recycled aggregate by microhardness test. Constr. Build. Mater. 40, 455-460. https:// doi.org/10.1016/j.conbuildmat.2012.09.114.

48. Zheng, C.; Lou, C.; Du, G.; Li, X.; Liu, Z.; Li, L. (2018) Mechanical properties of recycled concrete with demolished waste concrete aggregate and clay brick aggregate. Results Phys. 9, 1317-1322. https:///oi.org/10.1016/j. rinp.2018.04.061.

49. Bustillo Revuelta, M. (2010) Manual de RCD y áridos reciclados, Fueyo editores, Madrid, (2010).

50. Sidorova, A. (2013) Estudio del efecto de la naturaleza del árido reciclado en la microestructura y propiedades de la zona de transición árido-pasta de cemento. Universitat Politècnica de Catalunya. Retreived from http://hdl.handle. net/10803/129569.

51. Al-bayati, H.K.A.; Tighe, S.L.; Baaj, H. (2016) Effect of Different Treatment Methods on the Interfacial Transition Zone Microstructure to Coarse Recycled Concrete Aggregate. In: Green Technol. Geotechical Mater. Eng. Session, 2016 Conference of the Transportation Association of Canada Toronto. Retreived from https://www.tac-atc.ca/ sites/default/files/conf_papers/al-bayati_.pdf.

52. Lo, Y.; Gao, X.F.; Jeary, A.P. (1999) Microstructure of pre-wetted aggregate on lightweight concrete. Build. Environ. 34 [6], 759-764. https://doi.org/10.1016/S0360-1323 (98)00060-2. 